\title{
Molecular Cloning and Expression Profiles of Thermosensitive TRP Genes in Agasicles hygrophila
}

\author{
Dong Jia ${ }^{1}$, Zhouyu Ji ${ }^{1}$, Xiaofang Yuan ${ }^{1}$, Bin Zhang ${ }^{2}$, Yanhong Liu ${ }^{1}{ }^{\mathbb{C}}$, Jun Hu ${ }^{1}$, Yuanxin Wang ${ }^{1}$, \\ Xianchun $\mathrm{Li}^{3, *}$ and Ruiyan $\mathrm{Ma}^{1, *}$ \\ 1 College of Plant Protection, Shanxi Agricultural University, Taigu 030801, China; biodong@sxau.edu.cn (D.J.); \\ jzhouyu@126.com (Z.J.); xiaofyuu@foxmail.com (X.Y.); liuyanhong1984@126.com (Y.L.); \\ hujun.yx@163.com (J.H.); wangyuanx1992@163.com (Y.W.) \\ 2 College of Horticulture, Shanxi Agricultural University, Taigu 030801, China; jztgzhangbin@163.com \\ 3 Department of Entomology and BIO5 Institute, University of Arizona, Tucson, AZ 85721, USA \\ * Correspondence: 1xc@email.arizona.edu (X.L.); maruiyan2019@163.com (R.M.)
}

Received: 29 June 2020; Accepted: 11 August 2020; Published: 13 August 2020

Simple Summary: The increase of hot days with temperatures over $37^{\circ} \mathrm{C}$ in southern China due to global warming has led to summer collapse of the alligator weed flea beetle, an introduced biological agent for the invasive alligator weed. To promote understanding of the beetle's adaption/tolerance to hot temperatures, we obtained TRPA1, Painless, and Pyrexia, three thermosensitive transient receptor potential channel genes from the beetle, and analyzed their expression patterns across different developmental stages and hot temperatures. Their constitutive expressions were dramatically different from each other and stage-specific. As temperature increased, their expressions in eggs elevated to their peak levels at 30 or $37.5^{\circ} \mathrm{C}$, and then fell back to their preferred temperature levels at temperatures $>$ their peak temperatures. These results imply that (1) they may have different and stage-specific roles in perceiving high temperatures/chemicals and mediating the corresponding responses; and (2) their expressions may be decoupled from their activation. These findings lay a foundation for further understanding of the summer collapse of the beetle.

\begin{abstract}
Global warming has gradually reduced the control efficacy of Agasicles hygrophila against the invasive weed Alternanthera philoxeroides. To better understand the summer collapse of $A$. hygrophila populations, we cloned the cDNA sequences of the high temperature-sensing TRPA1, Painless, and Pyrexia from A. hygrophila, and analyzed their temporal expressions and the impacts of high temperatures on their expression in eggs, the most vulnerable stage of $A$. hygrophila to hot temperatures. All the three genes obtained had the signature domains of TRPA channels and were constitutively expressed in eggs, larvae (L1, L2, L3), pupae, and adults, but AhPainless had the highest expression, followed by AhPyrexia, and AhTRPA1. The lowest and highest expression stages were adult and pupae for AhTRPA1, egg and L3 for AhPainless, and pupae/adult and L2 for AhPyrexia. The expressions of AhTRPA1, AhPainless, and AhPyrexia remained low at the preferred temperature range of $25-28^{\circ} \mathrm{C}$, elevated to their peak levels at $37.5,30$, and $30^{\circ} \mathrm{C}$, respectively, then fell to their $25-28^{\circ} \mathrm{C}$ levels (AhTRPA1, AhPainless) or a lower level (AhPyrexia) at one or more temperatures $>30$ or $37.5^{\circ} \mathrm{C}$. These results suggest that their temperature-sensing roles and importance may be different, stage-specific, and their expression may be decoupled from their activation.
\end{abstract}

Keywords: activation; Alternanthera philoxeroides; expression profile; heat tolerance; thermosensation

\section{Introduction}

Temperature is the most important environmental factor affecting all aspects of insect life, such as growth, development, reproduction, behavior, and survival [1]. Insects must perceive the temperature 
autonomously to find the microenvironment most suitable for their growth and reproduction while avoiding hot or cold temperatures. Therefore, they have developed various temperature-sensing mechanisms during their evolution [2,3]. The transient receptor potential (TRP) channels associated with the organismal level of temperature sensation, known as "thermoTRP" channels [4], are among the most commonly used temperature-sensing mechanisms. As a family of cation channels located on the cell membrane of numerous animal cell types, TRP channels also mediate sensation of visual, auditory, tactile, olfactory, taste, mechanical cues [5-9]. ThermoTRP channels are thermally activated to trigger various temperature-dependent in vivo responses, such as thermosensation, thermotaxis, and regulation of cellular/tissue functions at physiological body temperature in mammals. For ectothermic insects, thermoTRP channels are essential for the insects to perceive changes in the ambient temperature and thus for their survival and behavioral responses [6].

Based on their homology and characteristics of structural domains, insect TRP channels are divided into seven subfamilies, i.e., TRPC (canonical), TRPA (ankyrin), TRPM (melastatin), TRPV (vanilloid), TRPN (no mechanoreceptor potential C, NOMPC), TRPP (polycystin), and TRPML (mucolipin) [6,10,11]. TRP channel genes have been detected in insects such as Drosophila melanogaster, Bombyx mori, Tribolium castaneum, Apis mellifera, Anopheles gambiae, and Bactrocera dorsalis [11-13]. The functions of insect TRP channels have been studied most thoroughly in D. melanogaster due to its simple neurons and facile genetic manipulation. In D. melanogaster, thermoTRPs related to temperature sensation mainly belong to three subfamilies: TRPA (TRPA1, Painless and Pyrexia), TRPC (TRP and transient receptor potential-like, TRPL), and TRPV (Inactive). Drosophila TRPC and TRPV subfamilies are conducive to sensing low temperatures below $17.5-18^{\circ} \mathrm{C}$ and thus are associated with cold sensation [14,15], whereas Drosophila TRPA subfamily is related to heat sensation and plays a central role in high temperature detection and behavioral responses to high temperature [16].

TRP channels are cation ion permeable channels formed as a homo- or hetero-tetramer. Each TRP channel subunit encoding by a TRP gene is often composed of an intracellular N-terminal domain, 3-6 Ankyrin repeats, a six transmembrane $\alpha$-helices domain, an ion pore-forming loop between transmembrane helices 5 and 6, and an intracellular C-terminal domain [8]. Each Ankyrin repeat is $\approx 33$ residues in length and is structurally consisting of two $\alpha$-helices connected by a $\beta$-turn [17]. TRPA subfamily is distinguished by having an unusually large number (>6) of Ankyrin repeats [17]. Ankyrin repeats occur in tandem arrangements to form elongated domains critical for many physiological processes [18].

There are three TRPA channels, including TRPA1, painless, and pyrexia, involved in detection and avoidance of high temperatures in D. melanogaster. TRPA1 is activated above $27^{\circ} \mathrm{C}$ [19] to trigger thermotaxis from moderately elevated temperature of about $31-35^{\circ} \mathrm{C}$ to a preferred temperature of $18-24{ }^{\circ} \mathrm{C}[20,21]$. Recent studies have showed that the temperature activation threshold of TRPA1 is actually variable, depending on the TRPA1 isoform [22-24]. Pyrexia is activated above $35{ }^{\circ} \mathrm{C}$ to prevent Drosophila from high-temperature-induced paralysis [25,26]. Painless is opened at temperatures greater than $42{ }^{\circ} \mathrm{C}$ to initiate avoidance of hazardous temperature by Drosophila larvae and adults [27]. In other insects such as T. castaneum, TRPA1, painless, and pyrexia work in a similar manner to mediate sensation of different ranges of high temperatures, heat tolerance, and acclimation [28]. In B. mori, maternal TRPA1 is also activated at temperatures higher than $21^{\circ} \mathrm{C}$ during the embryonic stage to stimulate the female adults to release diapause hormone into the progeny eggs, inducing egg diapause [29].

Although activation (channel opening) and transcription are two functional aspects of TRPA channels, the expressions of the above TRPA channels are underexplored. While both TRPA1 and painless are required for normal aversive behaviors to allyl isothiocyanate, a nociceptive allelochemical that D. melanogaster may encounter in its host plants, the two channels are expressed in different neurons of the peripheral (leg and labral sense organs) and central nervous systems [27,30]. Similarly, the spatiotemporal expression patterns of TRPA1, painless, and pyrexia are at least partially different in the oriental fruit fly (Bactrocera dorsalis) [13]. In rat where TRPA1 is activated by a wide range of 
environmental chemicals and decreases in temperature (at below $17^{\circ} \mathrm{C}$ ), cold temperature (five weeks at $+4 \pm 6^{\circ} \mathrm{C}$ ) does not affect its expression but inhibits the expression of TRPV3 that is activated at temperatures above $31^{\circ} \mathrm{C}$ [31]. For comparison, the rat TRPA1 activator formaldehyde enhances mRNA and protein levels of TRPA1, whereas the rat TRPA1 blocker menthol reduces TRPA1 expression [32].

The alligator weed flea beetle (Agasicles hygrophila Selman and Vogt) has been introduced from Argentina to successfully control the globally invasive weed Alternanthera philoxeroides (Mart.) Griseb in the United States, Australia, New Zealand, Thailand, and China [33,34]. The control efficacy of the beetle against the weed has reduced dramatically in recent years due to the increase of hot days with $0.5-2 \mathrm{~h}$ maximum temperatures over $37^{\circ} \mathrm{C}$ resulted from global warming in southern China [35]. While such hot summer permits the weed to proliferate rapidly, it suppresses the beetle population or even makes it collapse [36-39]. This is because the eggs of the beetle, the most vulnerable stage to heat stress, cannot tolerate temperatures over $37.5^{\circ} \mathrm{C}$ for a short period of $1 \mathrm{~h}$ [40]. To promote understanding of the adaption/tolerance of the beetle population to a short period of hot temperatures, we cloned the cDNA sequences of TRPA1, Painless, and Pyrexia, the three TRPA genes involved in detection and avoidance of high temperatures in insects, from the beetle $A$. hygrophila and analyzed the expression profiles of the three TRPA genes and the impacts of $1 \mathrm{~h}$ of hot temperatures on their expression. We found that the constitutive expressions of the three genes were dramatically different from each other, stage-specific, and their expression fell back to their preferred temperature levels at temperatures $>$ their peak temperatures. These results imply that (1) the three genes may have different and stage-specific roles in perceiving high temperatures/chemicals and mediating the corresponding behavioral responses; and (2) their expression may have nothing to do with their activation temperatures.

\section{Materials and Methods}

\subsection{Insect and Host Plant}

The A. hygrophila laboratory strain used in this study was established with a field collection from South China Agricultural University campus (Guangzhou, China) over 10 years ago. This laboratory strain has since been maintained on $A$. philoxeroides plants, which was initially collected from Yuhuan County, Zhejiang Province over 10 years ago, and has since been planted in greenhouses of Shanxi Agricultural University, in the insectary of Shanxi Agricultural University (Taigu, Shanxi, China) under standard conditions $\left(25 \pm 1{ }^{\circ} \mathrm{C}\right.$, light:dark $=14: 10 \mathrm{~h}$, relative humidity $\left.(\mathrm{RH})=85 \% \pm 5 \%\right)[40]$.

\subsection{Heat Shock of Beetle Eggs and Collection of Beetles of Different Stages}

A. philoxeroides plants with $A$. hygrophila eggs laid within $3 \mathrm{~h}(8-11 \mathrm{am})$ at $25^{\circ} \mathrm{C}$ were exposed to $25^{\circ} \mathrm{C}$ (control), $27.5,30,32.5,35,37.5,40$, or $42.5\left( \pm 0.5{ }^{\circ} \mathrm{C}\right)$ at $85 \% \pm 5 \% \mathrm{RH}$, which was equal to the average RH in the summer of southern China, the habitat of the alligator weed beetle, for $1 \mathrm{~h}$ [40]. The eggs were then gently detached from the weed leaves, flash-frozen with liquid nitrogen, and stored at $-80{ }^{\circ} \mathrm{C}$ for subsequent total RNA extraction. Three replicates of 20 egg masses (25-30 eggs per mass) each were performed for control and each temperature treatment. To ensure that the fluctuation of the tested temperature was $\leq \pm 0.5{ }^{\circ} \mathrm{C}$, the growth chambers with treated eggs were monitored and corrected in real time using HOBO U12 Temp/RH/Light/External Data Logger (Onset Computer Corporation, Bourne, MA, USA).

We also randomly collected, flash-frozen with liquid nitrogen, and stored at $-80^{\circ} \mathrm{C}$ three replicates of beetles of different developmental stages from the laboratory strain for subsequent total RNA extraction. These included 1-day-old eggs (20 egg masses per replicate), 1-day-old 1st (100-120 larvae per replicate), 2nd (80-100 larvae per replicate), and 3rd (60-80 larvae per replicate) instar larvae, 2-day-old pupae ( $48 \mathrm{~h}$ after boring into plant stems; 20 pupae per replicate), and 1-day-old adults (six males + six females per replicate). 


\subsection{RNA Extraction}

Total RNAs were extracted from the A. hygrophila samples of different developmental stages and the heat-shocked $A$. hygrophila egg samples prepared above using TRIzol reagent (Life Technologies, Carlsbad, CA, USA) according to the manufacturer's protocol. The concentration and purity of the obtained RNA samples were measured using BioPhotometer Plus (Eppendorf, Hamburg, Germany), and the integrity of each RNA sample was verified using $1 \%$ agarose gel electrophoresis.

\subsection{RT-PCR Cloning of Three TRPA Genes}

The RNA sample used for RT-PCR cloning of the three TRPA genes was prepared by pooling an equal amount of RNA from each of the six developmental stages. A total of $1 \mu \mathrm{g}$ of this pooled total RNA sample was reverse transcribed into cDNA using M-MLV Reverse Transcriptase (Promega, Madison, WI, USA). Then, $1 \mu \mathrm{L}$ of the resultant cDNA sample was used as the template to RT-PCR-amplify the cDNA sequences of TRPA1, painless, and pyrexia, respectively, in a $25 \mu \mathrm{L}$ reaction containing $12.5 \mu \mathrm{L}$ $2 \times$ Phanta Max Buffer, $1 \mu \mathrm{L}$ Phanta Max Super-Fidelity DNA Polymerase (Vazyme Biotech, Nanjing,

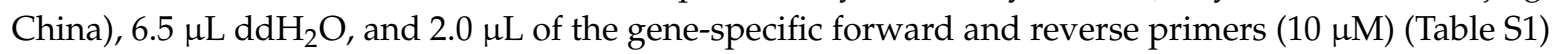
designed based on the contigs of each gene found in the full-length transcriptome of A. hygrophila [41]. The amplification conditions of PCR were pre-denaturation at $94^{\circ} \mathrm{C}$ for $3 \mathrm{~min}$, followed by 35 cycles of denaturation at $94{ }^{\circ} \mathrm{C}$ for $30 \mathrm{~s}$, annealing at $56^{\circ} \mathrm{C}$ for $30 \mathrm{~s}$, and elongation at $72{ }^{\circ} \mathrm{C}$ for $4 \mathrm{~min}$, as well as a final elongation at $72{ }^{\circ} \mathrm{C}$ for $5 \mathrm{~min}$. The obtained RT-PCR products of each gene were fractioned on a 1.2\% agarose gel, eluted using a MiniBEST Agarose Gel DNA Extraction Kit Ver.4.0 (TaKaRa, Dalian, China), and cloned into pMD ${ }^{\text {TM} 19-T ~ V e c t o r ~(T a K a R a, ~ D a l i a n, ~ C h i n a) . ~ T h r e e ~ p o s i t i v e ~ c l o n e s ~ f o r ~ e a c h ~}$ gene were sequenced (Sangon Biotech Co., Ltd., Shanghai, China).

\subsection{Sequence and Phylogenetic Analysis}

The open reading frames (ORFs) and amino acid sequences of the three TRPA genes were predicted using NCBI ORF finder (https://www.ncbi.nlm.nih.gov/orffinder/). Their isoelectric points and molecular masses were predicted using the ExPASy program ProtParam (http://web.expasy. org/protparam/). Their potential transmembrane domains were predicted using TMHMM Server v.2.0 (http://www.cbs.dtu.dk/services/TMHMM/). Their conserved TRPA domains were confirmed using Pfam and SMART (http://smart.embl-heidelberg.de/) [42]. Amino acid sequence alignments of A. hygrophila TRPA1 (AhTRPA1), Painless (AhPainless), Pyrexia (AhPyrexia) with their homologues from insects of different orders were done with the ClustalW program in MEGA7.0. The neighbor-joining phylogenetic trees of the three TRPA proteins were constructed using the p-distance model in MEGA7.0 program using [43]. Node support was assessed using a bootstrap procedure based on 1000 replicates.

\subsection{Reverse Transcription Quantitative PCR (RT-qPCR)}

A total of $800 \mathrm{ng}$ of each RNA sample were used as the template to synthesize the first-strand cDNA using a PrimeScript RT reagent Kit with gDNA Eraser (Perfect Real Time) (TaKaRa, Dalian, China). Reverse transcription quantitative PCR (RT-qPCR) analyses of the expression of the three TRPA genes were performed on an ABI 7500 (Applied Biosystems, Foster City, CA, USA) with SYBR Green Real-time PCR Master Mix (Toyobo, Osaka, Japan). Their gene-specific primers (Table S1) to amplify an 80-150-bp product were designed using online software primer3 (http://primer3.ut.ee). The PCR conditions were $95^{\circ} \mathrm{C}$ for $2 \mathrm{~min}$, followed by 40 cycles of $95^{\circ} \mathrm{C}$ for $15 \mathrm{~s}, 60^{\circ} \mathrm{C}$ for $15 \mathrm{~s}$, and $72{ }^{\circ} \mathrm{C}$ for $30 \mathrm{~s}$. After the final PCR cycle of each gene, melting curve was yielded to verify the absence of junk by measuring the fluorescence from 60 to $95^{\circ} \mathrm{C}$. The RPS18 and $\beta$-actin genes were used as the internal reference genes for RT-qPCR analyses of the three TRPA genes in heat-shocked eggs [44], whereas the RPS18 and RPL13a genes were used as the internal reference genes for RT-qPCR analyses of the three TRPA genes in beetles of different developmental stages [45]. 
For each target (i.e., TRPA genes here) and reference gene, we had three biological replicates (RNA samples) of three technical repeats each. The normalized expression level of each TRPA gene was calculated according to the following two equations [46].

$$
\begin{aligned}
& \text { Expression level }=\left(1+E_{\text {gene }}\right)^{-C t_{\text {gene }}}
\end{aligned}
$$

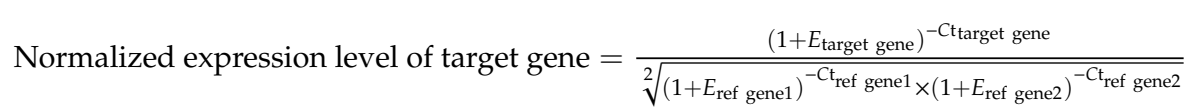

One-way ANOVA followed by Tukey's honest significant difference (HSD) test at $p<0.05$ was performed to determine if the normalized expression level of AhTRPA1, AhPailess, or AhPyrexia was significantly different among different developmental stages or different temperature treatments using SPSS 21.0 software (IBM, Armonk, NY, USA). All the histograms were drawn using SigmaPlot 12.5 (Systat Software Inc., San Jose, CA, USA).

\section{Results}

\subsection{Cloning and Sequence Analysis of A. hygrophila TRPA Genes}

The complete ORF of the A. hygrophila TRPA1 (AhTRPA1) gene is $3681 \mathrm{bp}$ in length and encodes a protein of 1226 amino acids, with a molecular mass of $138.90 \mathrm{kDa}$ and an isoelectric point of 7.42. It contains 14 ankyrin repeats from amino acid (AA) $151-666$ at the N-terminus and six ion channel-forming transmembrane domains from AA 807-1063 at the C-terminus (Figure 1), (Figure S1). The complete ORF of AhPainless gene is $2772 \mathrm{bp}$ in length and encodes a protein of 923 amino acids, with a molecular mass of $106.15 \mathrm{kDa}$ and an isoelectric point of 7.45. AhPainless has seven ankyrin repeats located in AA 62-420 at the N-terminus, and six ion channel-forming transmembrane domains located in AA 532-772, and a coiled coil in AA 891-923 at the C-terminus (Figure 1), (Figure S2). The complete ORF of the AhPyrexia gene is $2934 \mathrm{bp}$ in length and encodes a protein of 977 amino acids, with a molecular mass of $110.10 \mathrm{kDa}$ and an isoelectric point of 6.21. AhPyrexia contains eight Ankyrin repeats located in 190-459 at N-terminus, six ion channel-forming transmembrane domains located in in AA 554-809, and a coiled coil in AA 927-967 at the C-terminus (Figure 1), (Figure S3).

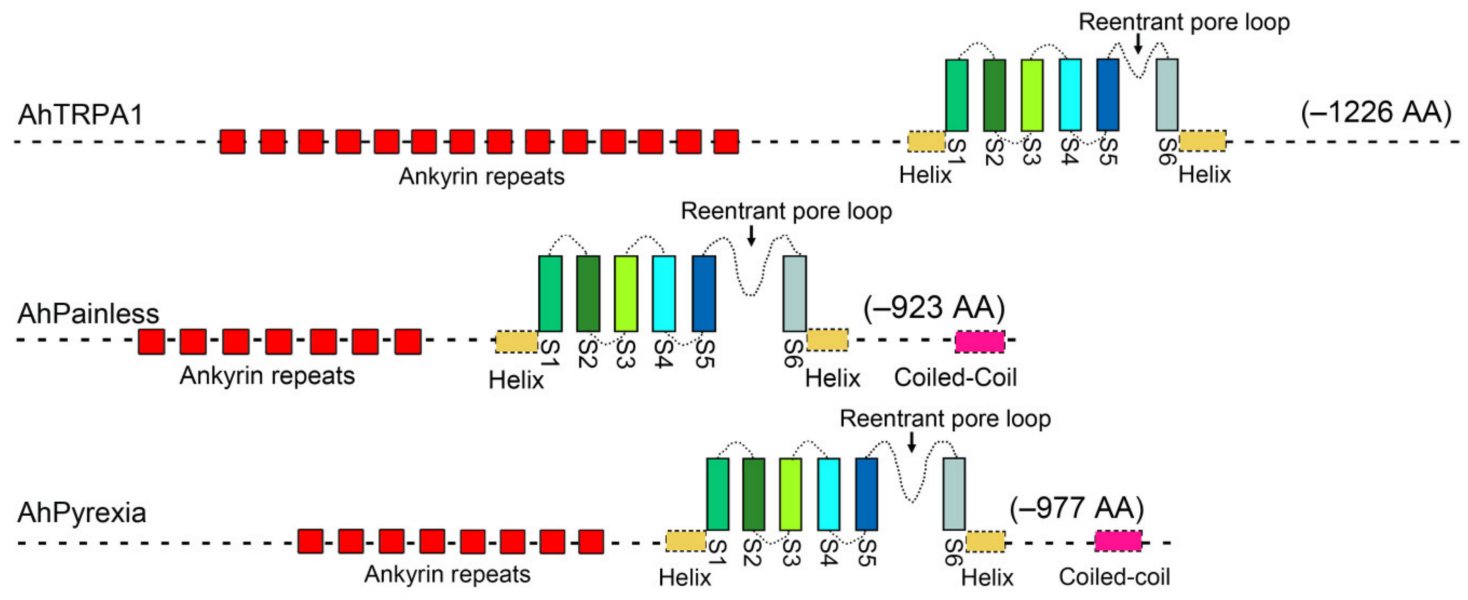

Figure 1. Predicted structural domains of TRPA channels. AhTRPA1, AhPainless, and AhPyrexia were three TRPA channels of Agasicles hygrophila, all of which have six transmembrane damains (S1-S6), and a reentrant pore loop between transmembrane domains S5 and S6. 


\subsection{Phylogenetic Analysis of A. hygrophila TRPAs with TRPs from Other Insects}

Phylogenetic analysis of AhTRPA1, AhPainless, and AhPyrexia with 87 TRPs from 10 species of four insect orders (Coleoptera, Diptera, Hemiptera, and Lepidoptera) placed the 90 insect TRPs in seven TRP subfamilies including TRPM, TRPC, TRPP, TRPML, TRPV, TRPA, and TRPN (Figure 2). Consistent with their structural characteristics, AhTRPA1, AhPainless, and AhPyrexia were clustered with other insect TRPA1, Painless and Pyrexia in the TRPA subfamily, respectively. Within the TRPA1, Painless, and Pyrexia branches, AhTRPA1, AhPyrexia, and AhPainless formed a smaller branch with TRPA1, Painless, and Pyrexia from other Coleopteran insects, respectively (Figure 2).

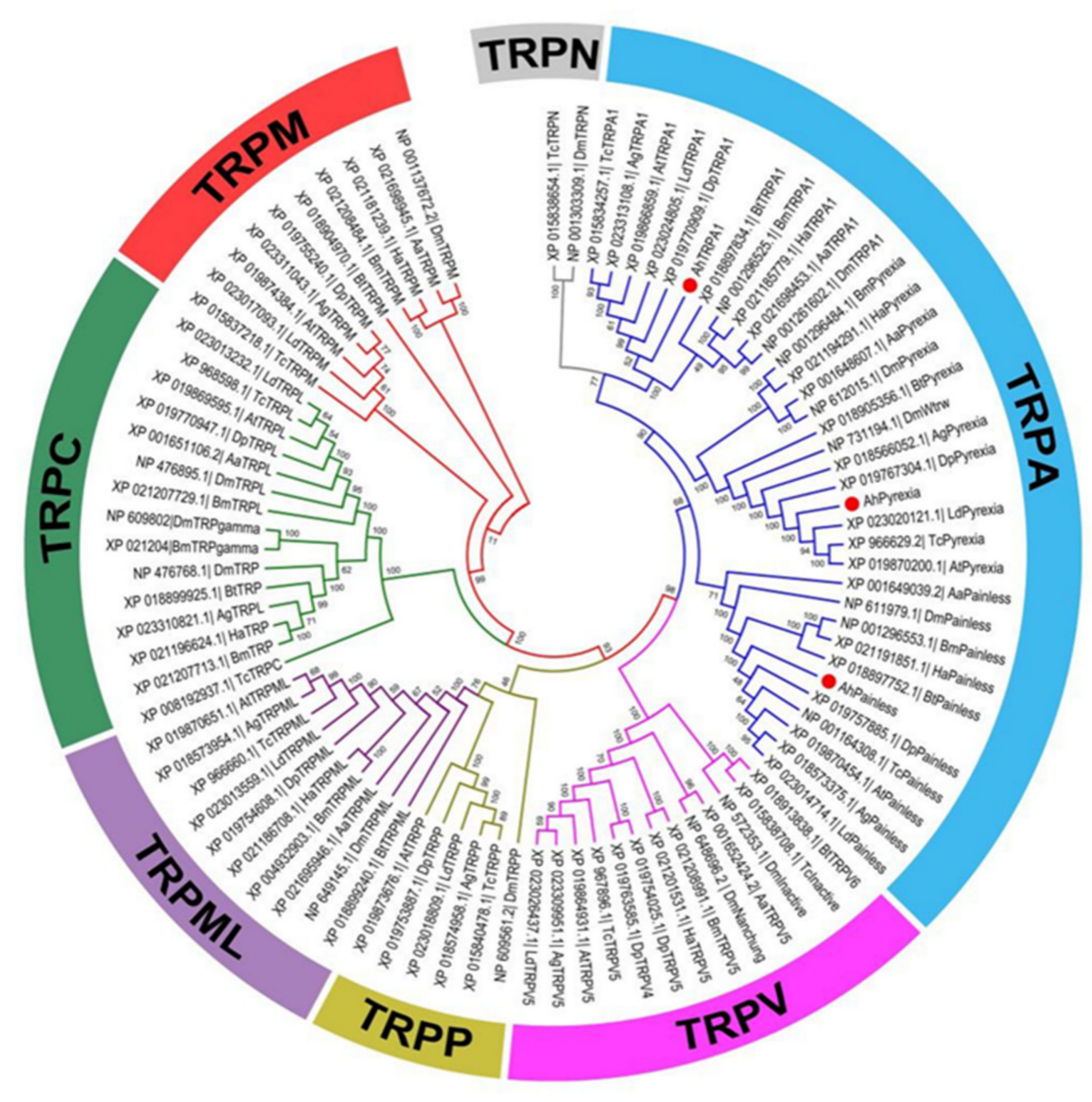

Figure 2. Phylogenetic analysis of transient receptor potentials (TRPs) in Agasicles hygrophila and other insects. Ninety TRP sequences from 11 species of four insect orders were used to construct this phylogenetic tree. The GenBank accession numbers of these sequences are listed in Table S2. The TRPA1, Painless, and Pyrexia of Agasicles hygrophila are represented by red dot "•".

\subsection{Temporal Expression Patterns of AhTRPA1, AhPainless, and AhPyrexia}

The basal expression levels of the three genes during different developmental stages were analyzed by RT-qPCR. The results showed that the three $A$. hygrophila TRPA genes were constitutively expressed in all developmental stages, but their expression levels differed dramatically (Figure 3). AhPainless had the highest expression, followed by AhPyrexia, and AhTRPA1. Overall, the expression of AhTRPA1 increased as the life stage advanced from egg to pupa and peaked in the pupal stage. However, the differences in the expression of AhTRPA1 were not significant between egg and different larval stages $(p>0.05)$, and the lowest expression of AhTRPA1 was observed in the adult stage (Figure $3 \mathrm{~A})$. 

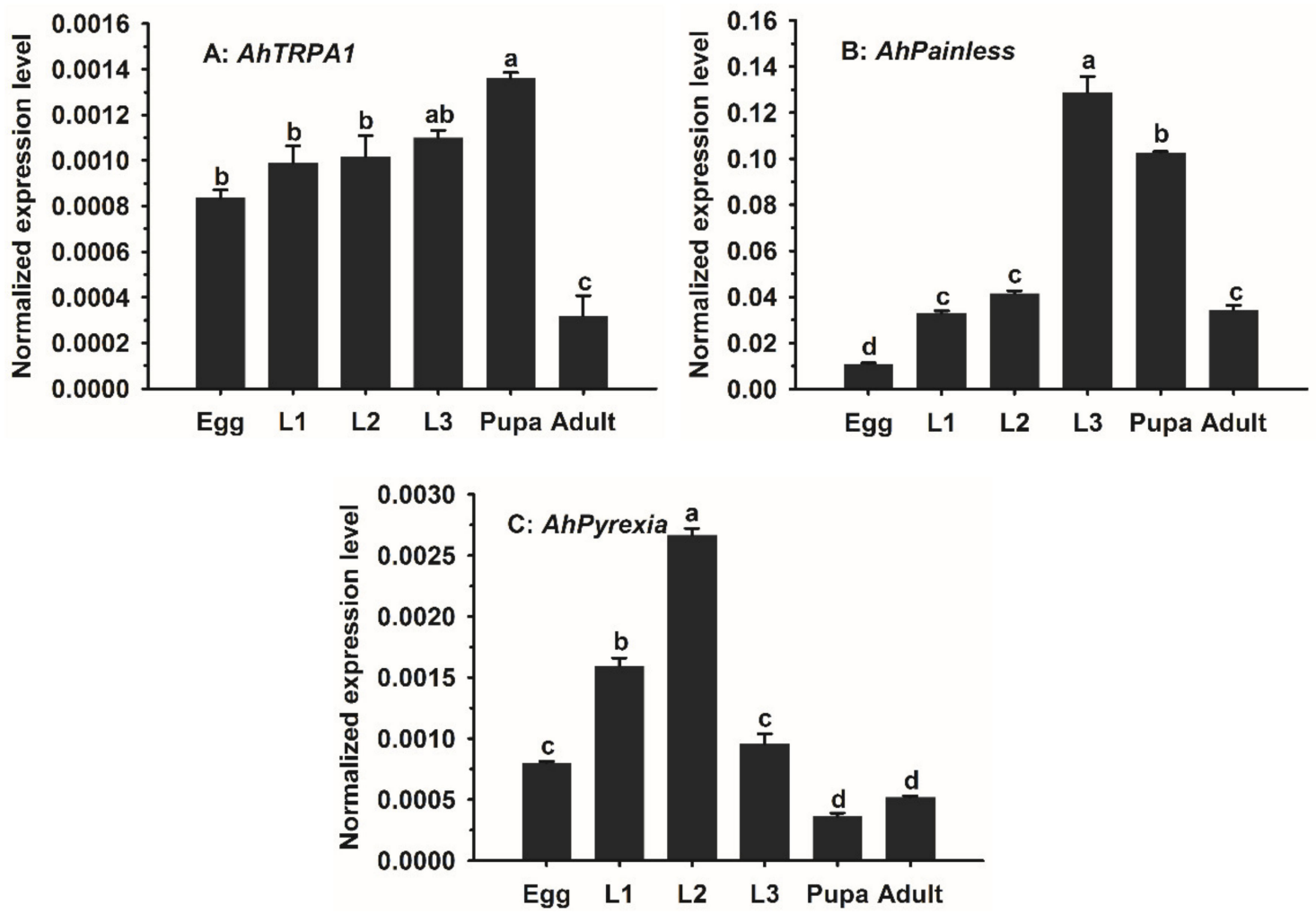

Figure 3. Developmental expression profiles of (A) AhTRPA1, (B) AhPainless, and (C) AhPyrexia in Agasicles hygrophila. Each developmental stage comprised three biological replicates. Data of the bar chart are expressed as mean \pm SE. The differences in the expression during different developmental stages were analyzed using one-way ANOVA and Turkey's honest significant difference (HSD) test. Different lowercase letters represent significant differences at $p<0.05$.

The expression level of AhPainless increased gradually from the egg to the third-instar larval stage (L3), and then gradually decreased from the third-instar larval stage to pupal and adult stages (Figure 3B). Multiple comparison showed that the third-instar larvae had the highest level of AhPainless, followed by pupae, then L1, L2 and adults, and finally eggs. The expression levels of L3, pupae, and adults were 11.8, 9.4, and 3.1 times that of eggs, respectively (Figure 3B).

The expression level of AhPyrexia was the highest in L2, followed by L1, egg and L3, and finally pupae and adults (Figure 3C). The expression of AhPyrexia in L2 was significantly higher than in L1. No significant difference in AhPyrexia expression was found between egg and L3 as well as between pupae and adults. L1 had significantly greater expression of AhPyrexia than did egg and L3. Both egg and L3 exhibited significantly higher expression of AhPyrexia than pupae and adults (Figure 3C).

\subsection{Impacts of Heat Shock on the Expression of AhTRPA1, Ahpainless, and AhPyrexia}

As egg was the most vulnerable stage of $A$. hygrophila to hot temperature in the summer [40], we exposed its eggs to 25 (control), 27.5, 30, 32.5, 35, 37.5, 40, or $42.5^{\circ} \mathrm{C}$ for $1 \mathrm{~h}$ and then analyzed the expressions of AhTRPA1, AhPainless, and AhPyrexia genes in the A. hygrophila eggs treated with one of the eight different temperatures. The expression of AhTRPA1 remained unchanged from $25-35^{\circ} \mathrm{C}$, sharply elevated 7.3-fold to its highest level (peak expression) at $37.5^{\circ} \mathrm{C}$, dramatically reduced 6.0 -fold at $40{ }^{\circ} \mathrm{C}$, and finally dropped back to the expression level of $25-35^{\circ} \mathrm{C}$ at $42.5^{\circ} \mathrm{C}$ (Figure $4 \mathrm{~A}$ ). The expression of AhPainless did not change significantly with the increase of temperature except for 30 and $42.5^{\circ} \mathrm{C}$ that significantly induced expression of this gene (Figure $4 \mathrm{~B}$ ). The peak expression of AhPainless occurred at $30^{\circ} \mathrm{C}$, which was marginally higher than that at $42.5^{\circ} \mathrm{C}$ (Figure $4 \mathrm{~B}$ ). Similarly, the expression of AhPyrexia did not change significantly with the increase of temperature except for 
$35{ }^{\circ} \mathrm{C}$ (Figure 4C). The expression of AhPyrexia at $35^{\circ} \mathrm{C}$ was significantly lower than that at $25,27.5,30$, and $42.5^{\circ} \mathrm{C}$, respectively (Figure $4 \mathrm{C}$ ).

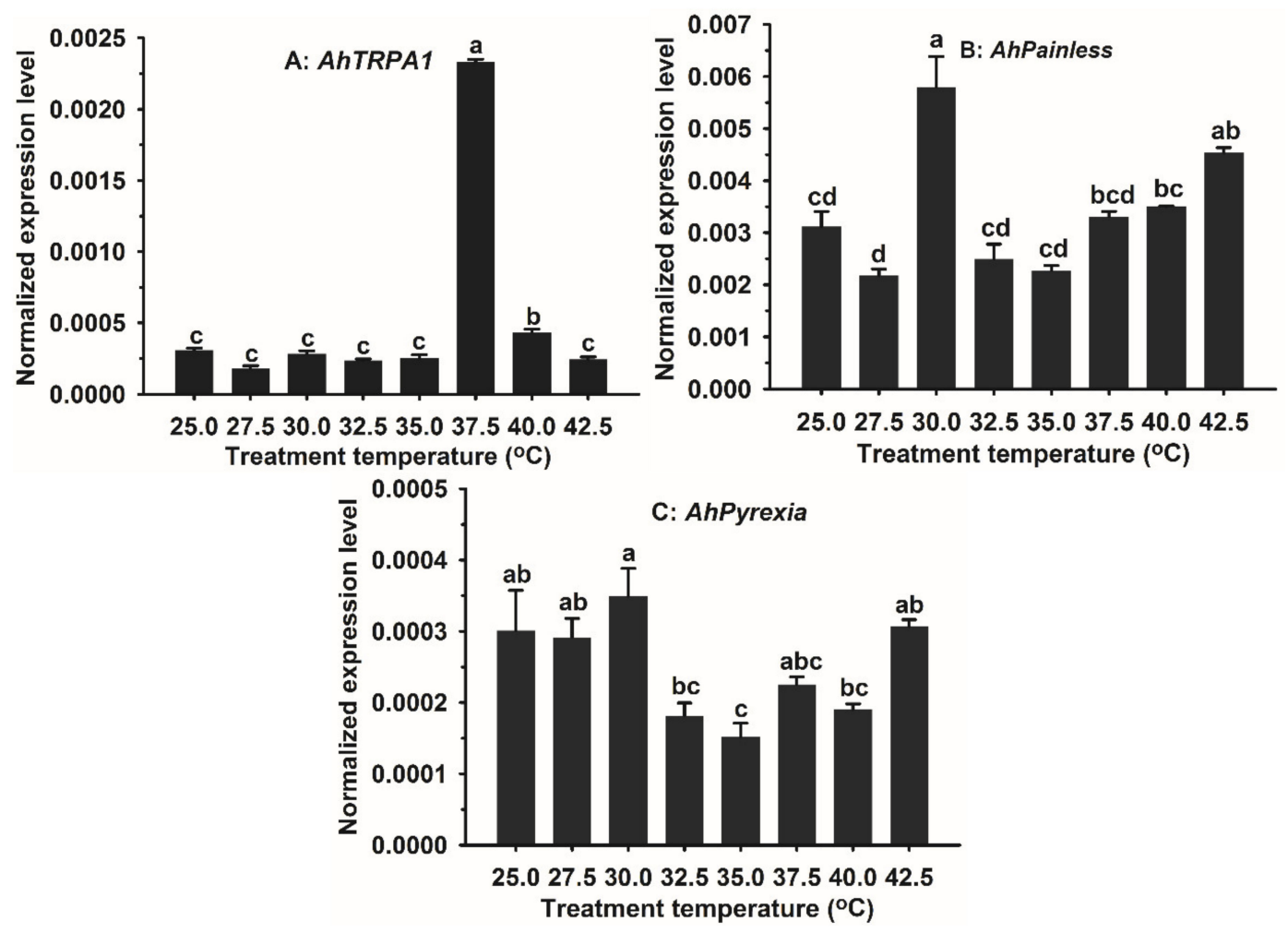

Figure 4. Impacts of temperature on the expression of (A) AhTRPA1, (B) AhPainless, and (C) AhPyrexia in Agasicles hygrophila eggs. Each treatment included three biological replicates. Data of the bar chart are represented by mean \pm SE. Differences in expression at different high temperatures were analyzed using one-way ANOVA and Turkey's HSD test. Different lowercase letters represent significant difference at $p<0.05$.

\section{Discussion}

In this study, the "thermoTRP" channels TRPA1, Painless, and Pyrexia known to be activated by temperatures higher than the optimal temperature $\left(18-24^{\circ} \mathrm{C}\right)$ of $D$. melanogaster [16] and noncaptive allelochemicals [30] were cloned from the alligator weed flea beetle A. hygrophila that prefers living at $25-28{ }^{\circ} \mathrm{C}$ (Jia et al., personal observation) but often encounters hot temperature in the summer season of southern China [40]. The encoded protein sequences of the AhTRPA1, AhPainless, and AhPyrexia we obtained from A. hygrophila have 7-14 tandem ankyrin repeats (Anks) of about 33 amino acids each (Figure 1), (Figures S1-S3), a signature feature of the TRPA subfamily. The tandem repeat of multiple Anks may be the important component for these TRPA channels to sense and transmit temperature stimuli $[4,17,18]$. AhTRPA1, AhPainless, and AhPyrexia also have six highly conservative transmembrane helices (S1-S6) with a reentrant pore loop between the fifth and sixth transmembrane helices (Figure 1), the common structure feature of TRP channels [8,47]. These two features plus the finding that AhTRPA1, AhPyrexia, and AhPainless clustered with the TRPA1, Painless, and Pyrexia from other Coleopteran insects (Figure 2), respectively, confirm that the AhTRPA1, AhPyrexia, and AhPainless we cloned are the canonical TRPA1, Painless, and Pyrexia genes of A. hygrophila.

Analysis of the temporal expression patterns of AhTRPA1, AhPainless, and AhPyrexia reveals two common and two gene-specific features. One common feature of the three A. hygrophila TRPA genes is that they were all expressed at the six tested stages. This suggests they all play a role in sensing high temperatures/or chemicals and mediating the corresponding responses in every life stage of this 
beetle. Another common feature is that their expression levels varied significantly among different developmental stages. This indicates that they may have stage-specific functions and/or relative importance in sensing high temperatures/chemicals and mediating the corresponding responses. One of the two gene-specific features is that the lowest and highest expression stages were adult and pupae for AhTRPA1, egg and L3 larvae for AhPainless, and pupae/adult and L2 larvae for AhPyrexia. This led us to speculate that AhTRPA1, AhPainless, and AhPyrexia contribute the least and the most to thermosensory responses in adult and pupae, egg and L3 larvae, and pupae/adult and L2 larvae, respectively. Another gene-specific feature is that AhPainless had the highest expression, followed by AhPyrexia, and AhTRPA1. This suggests that AhPainless may play more important roles than AhPyrexia, and AhTRPA1 may be the least important one of the three TRPA genes. Consistent with our findings, such unequal and stage-specific expression of the three genes have been detected in other insects $[13,48,49]$.

While we do not know the exact temperature thresholds that activate/open AhTRPA1, AhPainless, and AhPyrexia, respectively, it is expected that the thresholds of the three TRPA channels should be higher than $25-28{ }^{\circ} \mathrm{C}$, the preferred living temperature range of this beetle (Jia, Personal observation). The inhibition of the high temperature $\left(>31^{\circ} \mathrm{C}\right)$ activated rat TRPV3 expression by cold temperature [31] as well as the inhibition and induction of rat TRPA1 by its blocker menthol and activator formaldehyde [32] led us to hypothesize that the expression of the three A. hygrophila TRPA genes should remain at a constitutive level at $25-28^{\circ} \mathrm{C}$ and increase to a higher level once the temperature reaches their corresponding thresholds. Analysis of the expressions of the three genes in A. hygrophila eggs treated with different temperatures from 25 to $42.5^{\circ} \mathrm{C}$, however, did not support this prediction. This is because the expressions of AhTRPA1, AhPainless, and AhPyrexia elevated to their peak expression levels at $37.5,30$, and $30^{\circ} \mathrm{C}$, respectively, but all fell to their $25^{\circ} \mathrm{C}$ levels (AhTRPA1, AhPyrexia) or an even lower level (AhPainless) at one or more of the temperatures greater than 30 or $37.5^{\circ} \mathrm{C}$ (Figure 3). Two possibilities may explain this discrepancy. First, the activation or opening of the three A. hygrophila TRPA channels, unlike rat TRP channels [31,32], has nothing to do with their expression levels. Second, the three channels may be closed again at the temperatures greater than their peak expression temperatures $\left(T_{\text {peak }}\right)$. Functional determination of their activation and closing temperatures by two-electrode voltage clamp assays of Xenopus laevis oocytes heterologously expressed with AhTRPA1, AhPainless, or AhPyrexia are required to resolve the two possibilities.

Interestingly, the $T_{\text {peak }}$ of AhTRPA1 in A. hygrophila eggs, $37.5^{\circ} \mathrm{C}$, is exactly the same with the high temperature tolerance limit of $A$. hygrophila egg, at and above which the egg hatching rate is significantly reduced [40], the major cause of the summer collapse of $A$. hygrophila populations in southern China [36-39]. While use of the $T_{\text {peak }}$ of TRP genes has not been reported, the onset $\left(T_{\text {on }}\right)$ and peak ( $T_{\text {peak }}$ ) expression temperatures of heat shock proteins (HSPs) have been suggested as the useful indicators of the cold and hot temperature tolerance limits and thus northern and southern distribution boundaries of a given species [50]. Following this suggestion, $T_{\text {on }}$ and $T_{\text {peak }}$ of HSPs have been studied and applied as the biological indicators in evaluating thermal tolerance, diapause and geographical distribution of many species [51-56]. The fact that 21 out of 26 A. hygrophila HSP genes have a $T_{\text {peak }}$ of $37.5^{\circ} \mathrm{C}$ in eggs [44] proves the utility of the $T_{\text {peak }}$ of HSP gene as the heat tolerance limit indicator. Whether the perfect match of the $T_{\text {peak }}$ of AhTRPA1 with the hot temperature tolerance limit of $A$. hygrophila egg found here is just a coincidence or a common phenomenon in insects necessitates a correlation analysis of $T_{\text {peak }}$ of TRPA1 and heat tolerance limits in a number of insect species.

\section{Conclusions}

In this study, three thermosensitive TRP genes, including TRPA1, Painless, and Pyrexia in A. hygrophila were characterized and proved to belong to the canonical TRPA subfamily by structure domain and phylogeny analyses. We found the three TRPA genes were all expressed at the six tested stages but differed significantly in the expression level. As temperature increased from the preferred living temperature range $\left(25-28^{\circ} \mathrm{C}\right)$ of $A$. hygrophila, the expressions of the three TRPA genes in eggs 
elevated to their peak levels at 30 or $37.5^{\circ} \mathrm{C}$, but then all fell back to their $25^{\circ} \mathrm{C}$ or even lower levels. The $T_{\text {peak }}$ for AhTRPA1 in A. hygrophila eggs was the same with the high temperature tolerance limit of A. hygrophila eggs, but this could be just a coincidence.

Supplementary Materials: The following are available online at http://www.mdpi.com/2075-4450/11/8/531/s1, Figure S1: Putative amino acid sequence of AhTRPA1. Numbers on the left indicate the locations of amino acid residues. Shaded areas represent the predicted ankyrin repeats (Ank1-Ank14). Framed sequences were the predicted transmembrane segments (S1-S6), Figure S2: Putative amino acid sequence of AhPainless. Numbers on the left indicate the locations of amino acid residues. Shaded areas represent the predicted ankyrin repeats (Ank1-Ank7). Framed sequences were the predicted transmembrane segments (S1-S6), Figure S3: Putative amino acid sequence of AhPyrexia. Numbers on the left indicate the locations of amino acid residues. Shaded areas represent the predicted ankyrin repeats (Ank1-Ank8). Framed sequences were the predicted transmembrane segments (S1-S6), Table S1: Primers used for RT-PCR cloning of the full-length cDNA sequences of AhTRPA1, AhPailess, AhPyrexia and qPCR analysis of their expression, Table S2: The accession numbers of all TRPs used in phylogenetic analysis.

Author Contributions: Conceived and designed the experiments: D.J. and R.M.; Performed the experiments: D.J., Z.J., B.Z. and X.Y.; Analyzed the data: D.J., X.L., Y.W. and J.H.; Wrote the paper: D.J., X.L., Y.L. and R.M. All authors read and agreed to the published version of the manuscript.

Funding: This research was funded by the National Natural Science Foundation of China (31500304 and 31570436), Key R\&D Program in Shanxi Province (201803D221004-6 and 201803D221014-2), Applied Basic Research Program of Shanxi Province (201901D211354), and Talent Support Program of Shanxi Agricultural University (2016ZZ01).

Acknowledgments: We are grateful for the assistance of all staff and students in the Biosafety and Biocontrol Group, Shanxi Agricultural University at Taigu, Shanxi, China.

Conflicts of Interest: The authors declare no conflicts of interest. The funders had no role in the design of the study; in the collection, analyses, or interpretation of data; in the writing of the manuscript, or in the decision to publish the results.

\section{References}

1. Hoffmann, K.H. Metabolic and enzyme adaptation to temperature. In Environmental Physiology and Biochemistry of Insects; Hoffmann, K.H., Ed.; Springer: Berlin, Germany, 1984; pp. 1-32.

2. Barbagallo, B.; Garrity, P.A. Temperature sensation in Drosophila. Curr. Opin. Neurobiol. 2015, 34, 8-13. [CrossRef] [PubMed]

3. Bellemer, A. Thermotaxis, circadian rhythms, and TRP channels in Drosophila. Temperature 2015, 2, $227-243$. [CrossRef] [PubMed]

4. Laursen, W.J.; Anderson, E.O.; Hoffstaetter, L.J.; Bagriantsev, S.N.; Gracheva, E.O. Species-specific temperature sensitivity of TRPA1. Temperature 2015, 2, 214-226. [CrossRef] [PubMed]

5. Ramsey, I.S.; Delling, M.; Clapham, D.E. An introduction to TRP channels. Annu. Rev. Physiol. 2006, 68, 619-647. [CrossRef] [PubMed]

6. Venkatachalam, K.; Montell, C. TRP channels. Annu. Rev. Biochem. 2007, 76, 387-417. [CrossRef]

7. Montell, C. The history of TRP channels, a commentary and reflection. Pflug. Arch. Eur. J. Phy. 2011, 461, 499-506. [CrossRef]

8. Diaz-Franulic, I.; Poblete, H.; Mino-Galaz, G.; Gonzalez, C.; Latorre, R. Allosterism and structure in thermally activated transient receptor potential channels. Annu. Rev. Biophy. 2016, 45, 371-398. [CrossRef]

9. Clapham, D.E. TRP channels as cellular sensors. Nature 2003, 426, 517-524. [CrossRef]

10. Montell, C. The TRP superfamily of cation channels. Sci. Signal. 2005, 2005, re3. [CrossRef]

11. Matsuura, H.; Sokabe, T.; Kohno, K.; Tominaga, M.; Kadowaki, T. Evolutionary conservation and changes in insect TRP channels. BMC Evol. Biol. 2009, 9, 228. [CrossRef]

12. Peng, G.; Shi, X.; Kadowaki, T. Evolution of TRP channels inferred by their classification in diverse animal species. Mol. Phylogenet. Evol. 2015, 84, 145-157. [CrossRef] [PubMed]

13. Su, H.A.; Bai, X.; Zeng, T.; Lu, Y.Y.; Qi, Y.X. Identification, characterization and expression analysis of transient receptor potential channel genes in the oriental fruit fly, Bactrocera dorsalis. BMC Genom. 2018, 19, 674. [CrossRef] [PubMed]

14. Kwon, Y.; Shen, W.L.; Shim, H.S.; Montell, C. Fine thermotactic discrimination between the optimal and slightly cooler temperatures via a TRPV channel in chordotonal neurons. J. Neurosci. 2010, 30, 10465-10471. [CrossRef] [PubMed] 
15. Fowler, M.A.; Montell, C. Drosophila TRP channels and animal behavior. Life Sci. 2013, 92, 394-403. [CrossRef] [PubMed]

16. Sokabe, T.; Tominaga, M. A temperature-sensitive TRP ion channel, Painless, functions as a noxious heat sensor in fruit flies. Commun. Integr. Biol. 2009, 2, 170-173. [CrossRef]

17. Cordero-Morales, J.F.; Gracheva, E.O.; Julius, D. Cytoplasmic ankyrin repeats of transient receptor potential A1 (TRPA1) dictate sensitivity to thermal and chemical stimuli. Proc. Natl. Acad. Sci. USA 2011, 108, E1184-E1191. [CrossRef]

18. Lishko, P.V.; Procko, E.; Jin, X.; Phelps, C.B.; Gaudet, R. The ankyrin repeats of TRPV1 bind multiple ligands and modulate channel sensitivity. Neuron 2007, 54, 905-918. [CrossRef]

19. Viswanath, V.; Story, G.M.; Peier, A.M.; Petrus, M.J.; Lee, V.M.; Hwang, S.W.; Patapoutian, A.; Jegla, T. Opposite thermosensor in fruitfly and mouse. Nature 2003, 423, 822-823. [CrossRef]

20. Rosenzweig, M.; Brennan, K.M.; Tayler, T.D.; Phelps, P.O.; Patapoutian, A.; Garrity, P.A. The Drosophila ortholog of vertebrate TRPA1 regulates thermotaxis. Gene Dev. 2005, 19, 419-424. [CrossRef]

21. Kwon, Y.; Shim, H.-S.; Wang, X.; Montell, C. Control of thermotactic behavior via coupling of a TRP channel to a phospholipase C signaling cascade. Nat. Neurosci. 2008, 11, 871-873. [CrossRef]

22. Zhong, L.; Bellemer, A.; Yan, H.; Ken, H.; Jessica, R.; Hwang, R.Y.; Pitt, G.S.; Tracey, W.D. Thermosensory and nonthermosensory isoforms of Drosophila melanogaster TRPA1 reveal heat-sensor domains of a thermoTRP channel. Cell Rep. 2012, 1, 43-55. [CrossRef] [PubMed]

23. Luo, J.; Shen, W.L.; Montell, C. TRPA1 mediates sensation of the rate of temperature change in Drosophila larvae. Nat. Neurosci. 2017, 20, 34-41. [CrossRef] [PubMed]

24. Roessingh, S.; Stanewsky, R. The Drosophila TRPA1 channel and neuronal circuits controlling rhythmic behaviours and sleep in response to environmental temperature. Int. J. Mol. Sci. 2017, 18, 2028. [CrossRef]

25. Lee, Y.; Lee, Y.; Lee, J.; Bang, S.; Hyun, S.; Kang, J.; Hong, S.T.; Bae, E.; Kaang, B.K.; Kim, J. Pyrexia is a new thermal transient receptor potential channel endowing tolerance to high temperatures in Drosophila melanogaster. Nat. Genet. 2005, 37, 305-310. [CrossRef]

26. Neely, G.G.; Keene, A.C.; Duchek, P.; Chang, E.C.; Wang, Q.-P.; Aksoy, Y.A.; Rosenzweig, M.; Costigan, M.; Woolf, C.J.; Garrity, P.A. TrpA1 regulates thermal nociception in Drosophila. PLoS ONE 2011, 6, e24343. [CrossRef] [PubMed]

27. Tracey, W.D., Jr.; Wilson, R.I.; Laurent, G.; Benzer, S. Painless, a Drosophila gene essential for nociception. Cell 2003, 113, 261-273. [CrossRef]

28. Kim, H.G.; Margolies, D.; Park, Y. The roles of thermal transient receptor potential channels in thermotactic behavior and in thermal acclimation in the red flour beetle, Tribolium castaneum. J. Insect Physiol. 2015, 76, 47-55. [CrossRef]

29. Sato, A.; Sokabe, T.; Kashio, M.; Yasukochi, Y.; Tominaga, M.; Shiomi, K. Embryonic thermosensitive TRPA1 determines transgenerational diapause phenotype of the silkworm, Bombyx mori. Proc. Natl. Acad. Sci. USA 2014, 111, E1249-E1255. [CrossRef]

30. Mandel, S.J.; Shoaf, M.L.; Braco, J.T.; Silver, W.L.; Johnson, E.C. Behavioral aversion to AITC requires both painless and dTRPA1 in Drosophila. Front. Neural Circuits 2018, 12, 45. [CrossRef]

31. Voronova, I.P.; Tuzhikova, A.A.; Kozyreva, T.V. Expression of genes for temperature-sensitive TRP channels in the rat hypothalamus in normal conditions and on adaptation to cold. Neurosci. Behav. Physiol. 2014, 44, 565-570. [CrossRef]

32. Wang, X.L.; Cui, L.W.; Liu, Z.; Gao, Y.M.; Wang, S.; Li, H.; Liu, H.X.; Yu, L.J. Effects of TRPA1 activation and inhibition on TRPA1 and CGRP expression in dorsal root ganglion neurons. Neural Regen. Res. 2019, 14, 140-148. [PubMed]

33. Julien, M.; Sosa, A.; Chan, R.; Schooler, S.; Traversa, G. Alternanthera philoxeroides (martius) Grisebach-alligator weed. In Biological Control of Weed in Australia; Julien, M.H., McFadyen, R.E.C., Cullen, J.M., Eds.; CSIRO Publishing: Melbourne, Australia, 2012; pp. 43-51.

34. Liu, Y.H.; Jia, D.; Yuan, X.F.; Wang, Y.X.; Chi, H.; Ridsdill-Smith, T.J.; Ma, R.Y. Response to short-term cold storage for eggs of Agasicles hygrophila (Coleoptera: Chrysomelidae), a biological control agent of alligator weed Alternanthera philoxeroides (Caryophyllales: Amaranthaceae). J. Econ. Entomol. 2018, 11, 1569-1576. [CrossRef] [PubMed]

35. Zhang, W.; Zhao, F.; Hoffmann, A.A.; Ma, C.S. A single hot event that does not affect survival but decreases reproduction in the diamondback moth, Plutella xylostella. PLoS ONE 2013, 8, e75923. [CrossRef] [PubMed] 
36. Li, H.; Li, M.; Li, D. The biological control of alligator weed, Alternanthera philoxeroides in china. World Agric. 2000, 2, 36.

37. Wu, L.; Tian, S.; Wang, X.; Mai, Y.; Chen, R. Biological observation of Agasicles hygrophila in Guangdong. Chin . J. Biol. Control 2000, 16, 144-145.

38. Li, Y.; Fu, J.; Guo, J.; Zhu, X.; Huang, S.; Wan, F. Effects of release density on the population dynamics of the biocontrol agent, Agasicles hygrophila (coleoptera: Chrysomelidae). J. Biosaf. 2011, 20, 275-280.

39. Zhao, M.T.; Wang, Y.; Zhou, Z.S.; Wang, R.; Guo, J.Y.; Wan, F.H. Effects of periodically repeated heat events on reproduction and ovary development of Agasicles hygrophila (Coleoptera: Chrysomelidae). J. Econ. Entomol. 2016, 109, 1586-1594. [CrossRef] [PubMed]

40. Jia, D.; Yuan, X.F.; Liu, Y.H.; Xu, C.Q.; Wang, Y.X.; Gao, L.L.; Ma, R.Y. Heat sensitivity of eggs attributes to the reduction in Agasicles hygrophila population. Insect Sci. 2020, 27, 159-169. [CrossRef] [PubMed]

41. Jia, D.; Wang, Y.; Liu, Y.; Hu, J.; Guo, Y.; Gao, L.; Ma, R. SMRT sequencing of full-length transcriptome of flea beetle Agasicles hygrophila (Selman and Vogt). Sci. Rep. 2018, 8, 2197. [CrossRef]

42. Letunic, I.; Bork, P. 20 years of the smart protein domain annotation resource. Nucleic Acids Res. 2018, 46, D493-D496. [CrossRef]

43. Kumar, S.; Stecher, G.; Tamura, K. MEGA7: Molecular evolutionary genetics analysis version 7.0 for bigger datasets. Mol. Biol. Evol. 2016, 33, 1870-1874. [CrossRef] [PubMed]

44. Jia, D.; Liu, Y.H.; Zhang, B.; Ji, Z.Y.; Wang, Y.X.; Gao, L.L.; Ma, R.Y. Induction of heat shock protein genes is the hallmark of egg heat tolerance in Agasicles hygrophila (Coleoptera: Chrysomelidae). J. Econ. Entomol. 2020. [CrossRef]

45. Jia, D.; Ji, Z.Y.; Liu, Y.H.; Zhang, B.; Ma, R.Y. Screening and validation of internal reference genes in different developmental stages of Agasicles hygrophila. J. Shanxi. Univ. 2020, 40, 53-58.

46. Cheng, Q.; Gu, S.; Liu, Z.; Wang, C.Z.; Li, X. Expressional divergence of the fatty acid-amino acid conjugate-hydrolyzing aminoacylase 1 (l-ACY-1) in Helicoverpa armigera and Helicoverpa assulta. Sci. Rep. 2017, 7, 8721. [CrossRef] [PubMed]

47. Rosasco, M.G.; Gordon, S.E. TRP channels: What do they look like? In Neurobiology of TRP Channels, 2nd ed.; Emir, T.L.R., Ed.; CRC Press/Taylor \& Francis: Boca Raton, FL, USA, 2017; pp. 1-9.

48. Wei, J.; Cao, D.; Yang, T.; Wang, G. Cloning and spatio-temporal expression of the thermoreceptor gene painless in pea aphids (Acyrthosiphon pisum). Sci. Agric. Sin. 2014, 47, 3799-3809.

49. Fu, T.; Hull, J.J.; Yang, T.; Wang, G. Identification and functional characterization of four transient receptor potential ankyrin 1 variants in Apolygus lucorum (Meyer-Dür). Insect Mol. Biol. 2016, 25, 370-384. [CrossRef]

50. Tomanek, L.; Somero, G.N. Evolutionary and acclimation-induced variation in the heat-shock responses of congeneric marine snails (genus Tegula) from different thermal habitats: Implications for limits of thermotolerance and biogeography. J. Exp. Biol. 1999, 202, 2925-2936.

51. Gehring, W.J.; Wehner, R. Heat shock protein synthesis and thermotolerance in Cataglyphis, an ant from the Sahara desert. Proc. Natl. Acad. Sci. USA 1995, 92, 2994-2998. [CrossRef]

52. Huang, L.H.; Kang, L. Cloning and interspecific altered expression of heat shock protein genes in two leafminer species in response to thermal stress. Insect Mol. Biol. 2007, 16, 491-500. [CrossRef]

53. Kenkel, C.; Sheridan, C.; Leal, M.; Bhagooli, R.; Castillo, K.; Kurata, N.; McGinty, E.; Goulet, T.; Matz, M.V. Diagnostic gene expression biomarkers of coral thermal stress. Mol. Ecol. Resour. 2014, 14, 667-678. [CrossRef]

54. Cheng, W.; Li, D.; Wang, Y.; Liu, Y.; Zhu-Salzman, K. Cloning of heat shock protein genes (hsp70, hsc70 and hsp90) and their expression in response to larval diapause and thermal stress in the wheat blossom midge, Sitodiplosis mosellana. J. Insect Physiol. 2016, 95, 66-77. [CrossRef] [PubMed]

55. Xiao, N.; Pan, L.L.; Zhang, C.R.; Shan, H.W.; Liu, S.S. Differential tolerance capacity to unfavourable low and high temperatures between two invasive whiteflies. Sci. Rep. 2016, 6, 24306. [CrossRef] [PubMed]

56. Zhang, B.; Peng, Y.; Zheng, J.; Liang, L.; Hoffmann, A.A.; Ma, C.S. Response of heat shock protein genes of the oriental fruit moth under diapause and thermal stress reveals multiple patterns dependent on the nature of stress exposure. Cell Stress Chaperones 2016, 21, 653-663. [CrossRef] [PubMed]

(C) 2020 by the authors. Licensee MDPI, Basel, Switzerland. This article is an open access article distributed under the terms and conditions of the Creative Commons Attribution (CC BY) license (http://creativecommons.org/licenses/by/4.0/). 